\title{
Fluidization characteristics of different sizes of quartz particles in the fluidized bed
}

\author{
Zi-Jian Wang ${ }^{1} \cdot$ Jun Tang ${ }^{1} \cdot$ Chun-Xi Lu ${ }^{1}$
}

Received: 15 May 2015/Published online: 26 July 2016

(c) The Author(s) 2016. This article is published with open access at Springerlink.com

\begin{abstract}
Fluidization characteristics of quartz particles with different sizes are experimentally investigated in a fluidized bed with an inner diameter of $300 \mathrm{~mm}$ and height of $8250 \mathrm{~mm}$. Results show that the average solid holdup increases with the increase in superficial gas velocity and the decrease in initial solid holdup in the dense zone of the fluidized bed. The average cross-sectional solid holdup decreases with increasing bed height and superficial gas velocity. The bed expansion coefficient increases with the increase in superficial gas velocity and the decrease in solid holdup. Correlations of average solid holdup, average cross-sectional solid holdup and bed expansion coefficient are also established and discussed. These correlations can provide guidelines for better understanding of the fluidization characteristics.
\end{abstract}

Keywords Fluidization characteristic - Solid holdup · Axial average section solid holdup · Bed expansion coefficient

\section{Introduction}

Oil sands are an alternative fossil fuel which is composed of $10 \%-12 \%$ (mass fraction) bitumen, $80 \%-85 \%$ sand and clay and $3 \%-5 \%$ water (Painter et al. 2010; Xu et al. 2008). In China, the total oil sands reserves are approximately 5.97 billion tons, but only 2.58 billion tons can be

Chun-Xi Lu

1cx725@sina.com

1 State Key Laboratory of Heavy Oil Processing, China University of Petroleum (Beijing), Beijing 102249, China

Edited by Xiu-Qin Zhu extracted and utilized with current technology, meaning great development and utilization potentials. Conventionally, there exist two methods for separation of bitumen from oil sands, the hot water separation method (Fan and Bai 2015; Ren 2011) that can only be used for water-wet oil sands (Zhao et al. 2014) and the solvent extraction method that can be used to process oil-wet oil sands, but it requires high treatment costs and can result in environmental pollution.

The pyrolysis method has also been reported to improve the bitumen recovery from oil-wet oil sands with better operation flexibility than the two methods mentioned above. Recently, a lot of research has been focused on the pyrolysis of oil sands in fixed beds (Zhang et al. 2014; Wang 2015). Meng et al. (2007) studied the pyrolysis behaviors of Tumuji oil sands (from Inner Mongolia, China) in fixed beds by thermogravimetry (TG), which is used to investigate the effects of heating rate on pyrolysis and reaction kinetics. Lu et al. (2008) made an investigation on extraction of bitumen from oil sands by a direct fluidized-bed coking method, as shown in Fig. 1. The pyrolysis of oil sands is carried out in the fluidized bed. Then, the coked oil sands particles are conveyed to the burner to burn out the coke in the particles. After that, the burned oil sands particles are quickly returned to the reactor, and the heat produced in the burner is also taken to the reactor by the burned oil sand particles for heating the raw oil sand feedstock and for the pyrolysis. This process can improve the bitumen recovery with heat balance and good operation feasibility. Research has indicated that there are significant differences between the pyrolysis and solvent extraction methods in terms of qualities of product. Gao et al. (2013) compared the products of Inner Mongolia oil sands processed, respectively, by organic solvent extraction and fluidized-bed thermal reaction (pyrolysis) 


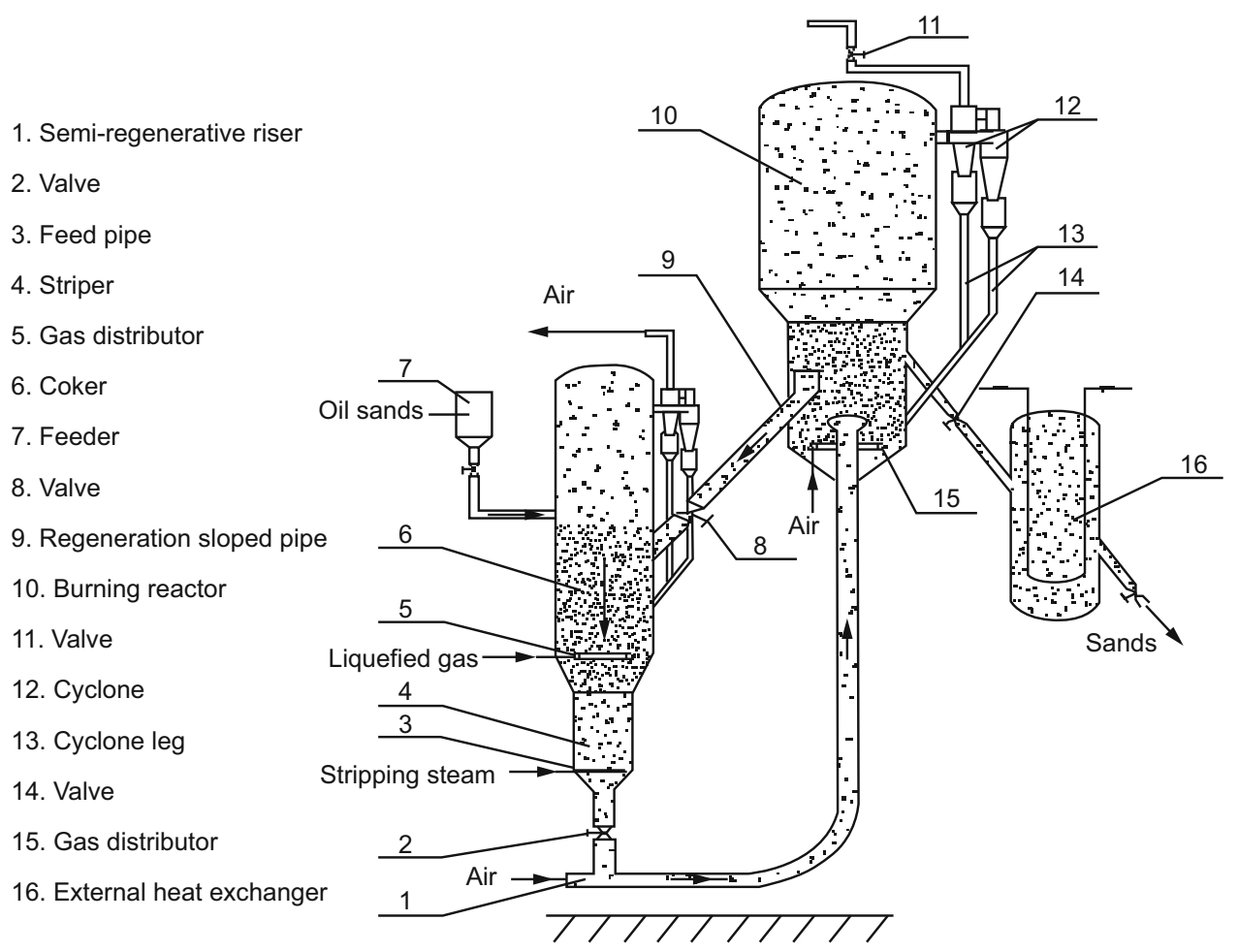

Fig. 1 Fluidized-bed coking process for oil sands

and found that the liquid product from the fluidized-bed thermal reaction had much lower density, viscosity and Conradson carbon residue than that from organic solvent extraction.

The unique features of direct fluidized-bed coking of oil sands enable it to be effectively used in the separation of bitumen from oil sands, where the fluidization characteristics of burned oil sands particles are of main concern. However, oil sands particles from different places and buried depths have wide and different size distributions. Therefore, the fluidization characteristics of different sizes of oil sand particles are critical for proper industrial design of fluidized beds.

The fluidization characteristics that have been studied mainly include the average solid holdup, the axial average solid holdup and the bed expansion coefficient (Ahuja and Patwardhan 2008; Sun et al. 2009; Zhang et al. 2015). The average solid holdup in the dense region is the key parameter for designing industrial fluidized beds. Avidan and Yerushalmi (1982) reviewed earlier studies on the effect of superficial gas velocity on the void ratio at high velocity. Lu et al. (1996a, b) have studied the average solid holdup in the dense zone in a turbulent bed and obtained a correlation of it. The axial average solid holdup distribution is crucial for investigation of the momentum transfer, mass transfer and heat transfer between gas and solid. Cai et al. (2008) found that the average dense zone solid holdup decreased with increasing height of the fluidized bed. Recently, Cui et al. (2014) studied the axial distribution and evolution of solid holdup in a fluidized bed-Riser coupled reactor and the effect of superficial gas velocity on the axial distribution of solid holdup. Zhu et al. (2014) studied the axial distribution of solid holdup in a pre-lifting structure with two strands of catalyst inlets. The bed expansion coefficient is widely used to determine the height of the dense bed. Lu et al. (1996a, b) systematically studied the bed expansion coefficient in a turbulent fluidized bed and proposed the empirical equation for prediction of the expansion height in the turbulent fluidized bed. Tang et al. (2012) studied the expansion characteristics of particle mixtures in the dense region of fluidized beds using the bed height-to-dense bed ratio. However, most of these experiments are concentrated on the fluidization characteristics of single-component particles, and the fluidization characteristics of multi-component particles are rarely reported.

The purpose of this work is to contribute to a better understanding and modeling of the fluidization characteristics of multi-component particles. For this objective, four kinds of particles with different sizes were used in Plexiglas experimental equipment for the study of multi-sized mixed particles. The models for the average solid holdup, the axial average section solid holdup and the bed expansion coefficient were developed. 


\section{Experimental method}

\subsection{Experimental apparatus and method}

Experiments were carried out in Plexiglas equipment with an inner diameter of $300 \mathrm{~mm}$ and a height of $8250 \mathrm{~mm}$, as shown in Fig. 2. A plate distributor with 100 holes of diameter $3 \mathrm{~mm}$ was fixed in the bottom of the fluidized bed. The opening area ratio is $1.1 \%$.

The pressures at different positions along the bed height were measured by using a $\mathrm{FXC}-\Pi / 32$ pressure transducer (Beijing Sensing Star Control Technology Co., Ltd. China), and the air superficial velocity was measured by a rotameter. The initial and dense bed height was measured by using a ruler adhered on the wall of the bed. As shown in Fig. 3, there were 16 measuring points on the wall along the bed height. More measuring points were installed in the dense bed. The average solid holdup $\varepsilon_{s}$ can be calculated by the following two equations,

$\Delta P=\Delta H \times g \times\left(\left(1-\varepsilon_{\mathrm{s}}\right) \rho_{\mathrm{g}}+\varepsilon_{\mathrm{s}} \rho_{\mathrm{p}}\right) \approx \Delta H \times g \times \varepsilon_{\mathrm{s}} \rho_{\mathrm{p}}$

$\varepsilon_{\mathrm{s}}=\frac{\Delta P}{\Delta H \times g \times \rho_{\mathrm{p}}}$

where $\Delta P$ means the pressure drop, $\mathrm{kPa} ; \Delta H$ is the distance between two measure points, $\mathrm{m}$; $\rho_{\mathrm{p}}$ is the density of particles, $\mathrm{kg} / \mathrm{m}^{3}$.

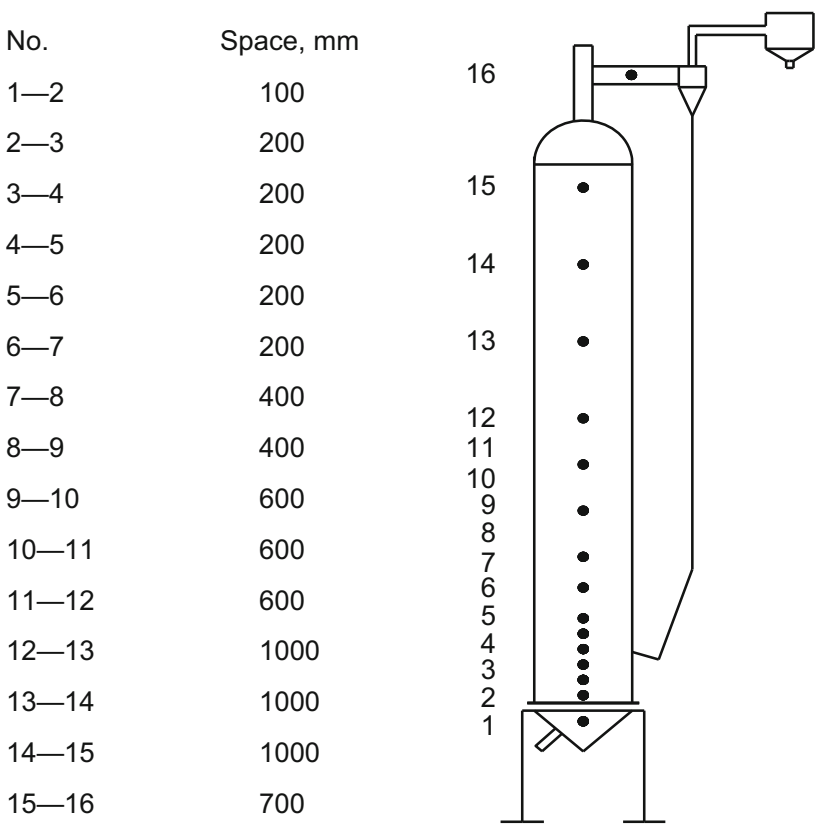

Fig. 3 Schematic diagram of axial measuring points

\subsection{Experimental materials}

In this experiment, the solid particles were Geldart A, B, C, and D quartz sand particles. The particle size distributions are shown in Fig. 4a-d, and the physical properties of the particles are given in Table 1, and Geldart has shown the difference between different types of Geldart particles (Geldart 1973). Ambient air was used as the fluidizing gas.

\section{Results and discussion}

\subsection{Average solid holdup}

Figures 5, 6 and 7 show the effect of different factors on the average solid holdup of A, B, C and D quartz sand particles in the dense phase. As shown in Fig. 5, the average solid holdup increased with increasing particle diameter. The slope of the curves decreased with the increase in particle diameter. This is reasonable because initial solid holdup increases with increasing particle diameter. When the particle diameter was small, initial solid holdup increased rapidly with increasing particle diameter. Thus, the average solid holdup increased with increasing initial solid holdup.

Figure 6 shows the effect of superficial gas velocity on the average solid content. It was clear that the average solid content decreased with the increasing superficial gas velocity because the solid holdup decreased with more gas passing through the dense phase. It was found that the average solid holdup of particles $\mathrm{C}$ and $\mathrm{D}$ decreased more greatly than that of particles $\mathrm{A}$ and $\mathrm{B}$ because of their different expansibilities.

Fig. 2 Schematic diagram of the experimental setup 
(a) Group A particles of quartz sand

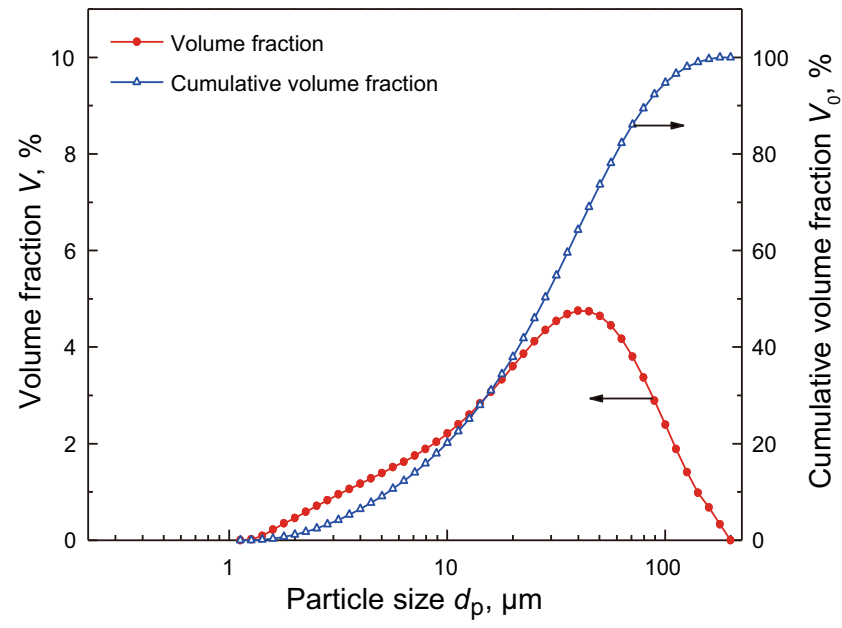

(c) Group C particles of quartz sand

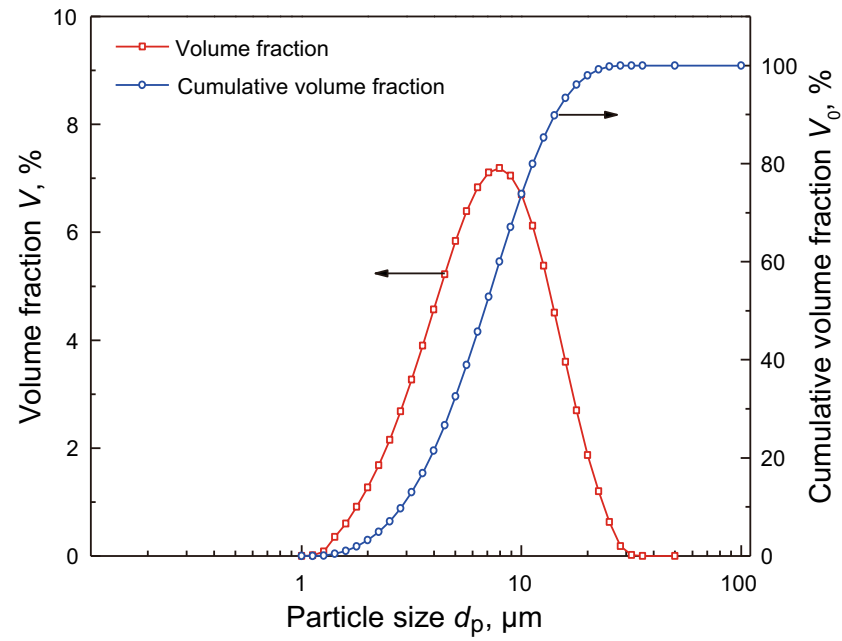

(b) Group B particles of quartz sand

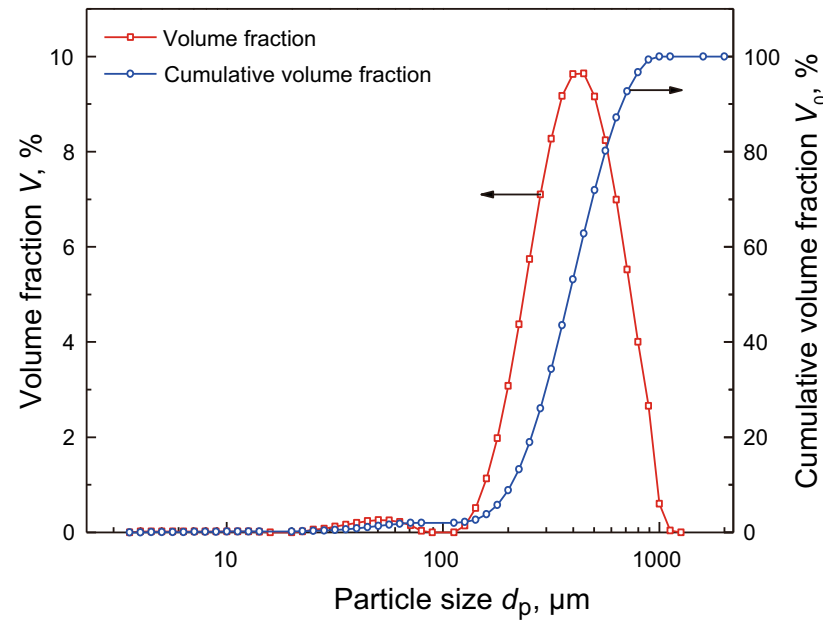

(d) Group D particles of quartz sand

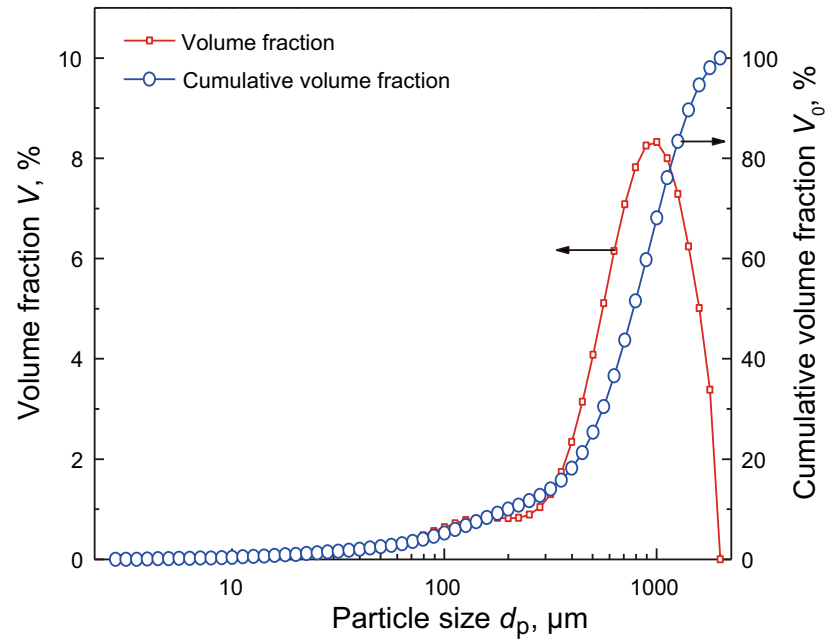

Fig. 4 Particle size distributions of the A, B, C and D quartz sand particles

Table 1 Physical properties of solid particles

\begin{tabular}{lccl}
\hline Particle & Mean diameter, $\mu \mathrm{m}$ & Bulk density, $\mathrm{kg} \mathrm{m}^{-3}$ & Particle density, $\mathrm{kg} \mathrm{m}^{-3}$ \\
\hline A quartz sand particle & 36.80 & 885 & 2451 \\
B quartz sand particle & 411.70 & 1255 & 2451 \\
C quartz sand particle & 7.80 & 613 & 2451 \\
D quartz sand particle & 810.70 & 1413 & 2451 \\
\hline
\end{tabular}

Figure 7 shows that the average solid content increased with increasing initial solid holdup. The initial solid holdup had a more significant effect on the average solid concentration than the particle diameter and superficial gas velocity shown in Figs. 5 and 6.

\subsection{Axial average section solid holdup}

Figure 8a-d shows the axial average solid holdup distribution of four kinds of different size quartz particles in the dense phase (when the initial bed height is 450 and $650 \mathrm{~mm}$ ). As shown in Fig. 8, the curves of the four different size ranges of particles were similar in shape. The average solid holdup decreased along the axial height and also decreased with an increase in superficial gas velocity. Since the density of the quartz particles is high, gravity has an appreciable impact on the axial average solid holdup distribution when particles travel against gravity. Gas began to accumulate into big bubbles along the axial height resulting in a higher void ratio along the axial height. When 


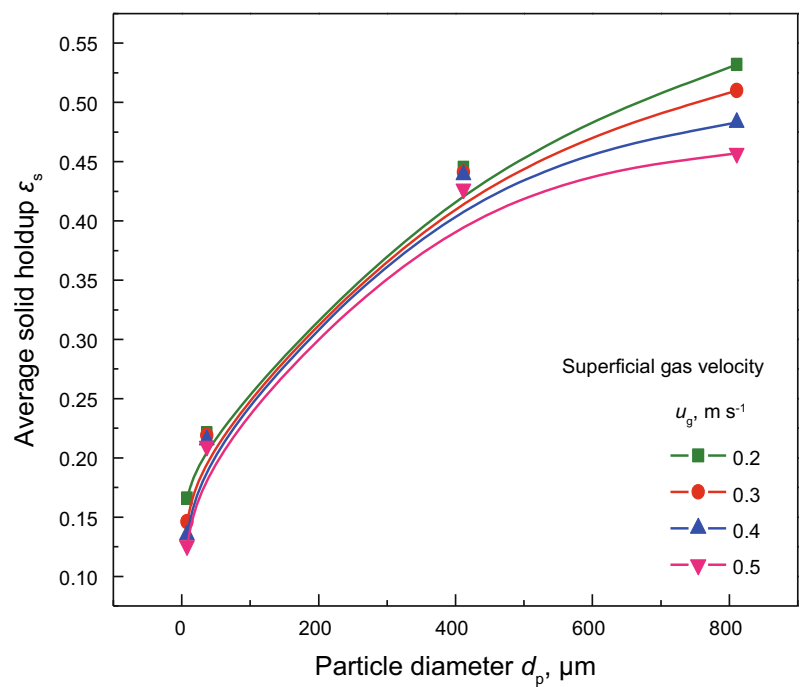

Fig. 5 Effect of particle diameter on average solid holdup in the dense phase

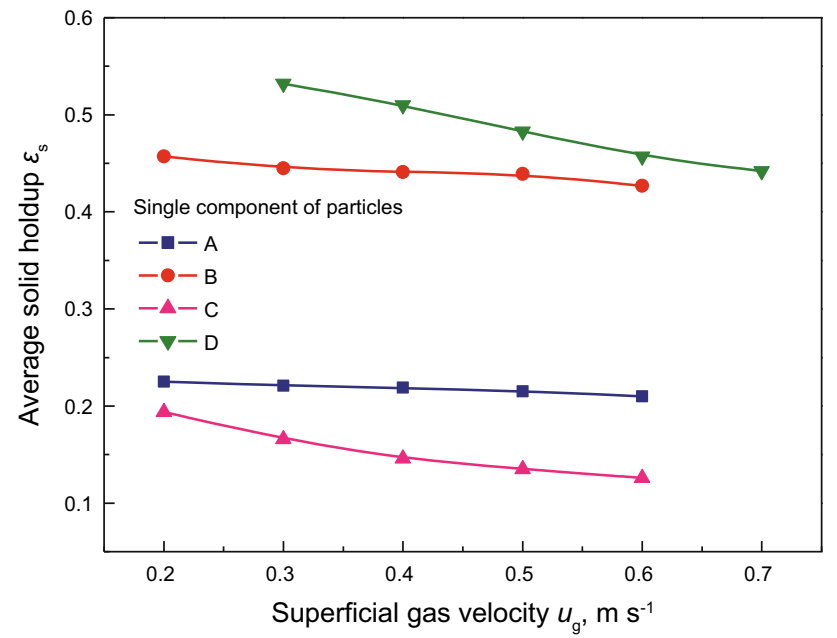

Fig. 6 Effect of superficial gas velocity on average solid holdup in the dense phase

the superficial gas velocity increased, two phenomena appeared. On the one hand, as a result of more and more bubbles appearing, the void ratio of the dense bed increased rapidly. On the other hand, the increasing diameters of bubbles followed by a rapid ascending motion led to the decrease in the void ratio. However, the first factor occupies the leading position. Because in this experiment, the flow regime was turbulent bed, on the impact of turbulent gas flow, bubbles were broken. Thus, when the superficial gas velocity increased, the diameter of bubbles decreased and the number of bubbles increased. As a result, the average solid holdup decreased with increasing superficial gas velocity. Compared with particles A, B and $\mathrm{D}$, the average solid holdup of particles $\mathrm{C}$ decreased

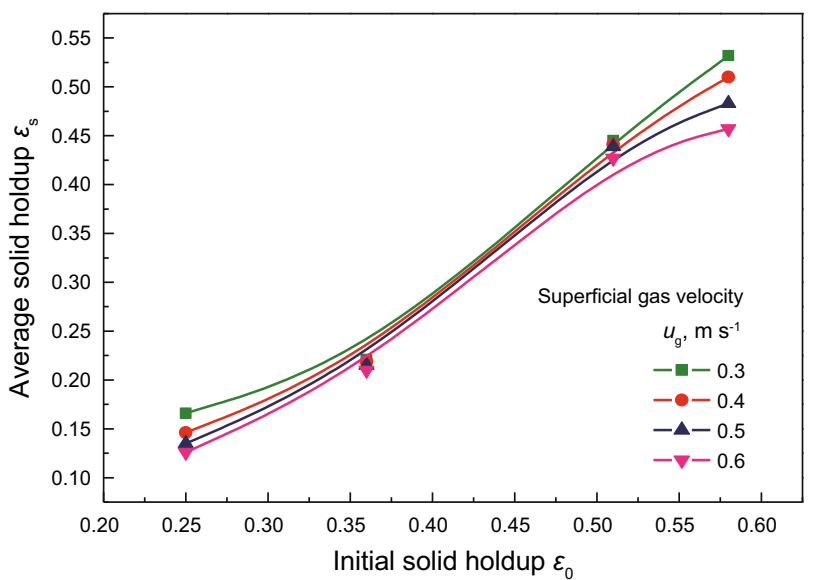

Fig. 7 Effect of initial solid holdup on average solid holdup in the dense phase

drastically with the increase in superficial gas velocity. This clearly verified that the smaller the diameter of particles was, the smaller the diameter of bubbles was.

\subsection{Bed expansion coefficient}

Two methods are generally used to calculate the bed expansion coefficient. One is based on the bed height ratio $\left(R_{h}\right)$, which means the ratio of the dense bed height to the initial bed height which can be regarded as the bed expansion coefficient. The other is based on the solid content ratio $\left(R_{\varepsilon}\right)$, which represents the ratio of initial solid holdup to average solid holdup in the dense phase. These two equations are shown as follows,

$R_{h}=\frac{H}{H_{0}}$

$R_{\varepsilon}=\frac{\varepsilon_{0}}{\varepsilon_{\mathrm{s}}}$

where $H$ means the dense bed height, m, and $H_{0}$ means the initial bed height, m. The method based on $R_{h}$ can be used to calculate and measure bed expansion coefficient easily when the superficial gas velocity was low. As for high superficial gas velocity, which will cause more fine particles being carried into the dilute phase, the method above exposed shortcomings by getting the result that $R_{h}$ decreased with increasing superficial gas velocity. It is contradictory to the actual fact that the bed expansion coefficient increases with the increasing superficial gas velocity. On the contrary, the method based on $R_{\varepsilon}$ can be used under the condition of high superficial gas velocity. Thus, the bed expansion coefficient of the four sizes of quartz particles was calculated by using the method based on solid content ratio $\left(R_{\varepsilon}\right)$. 

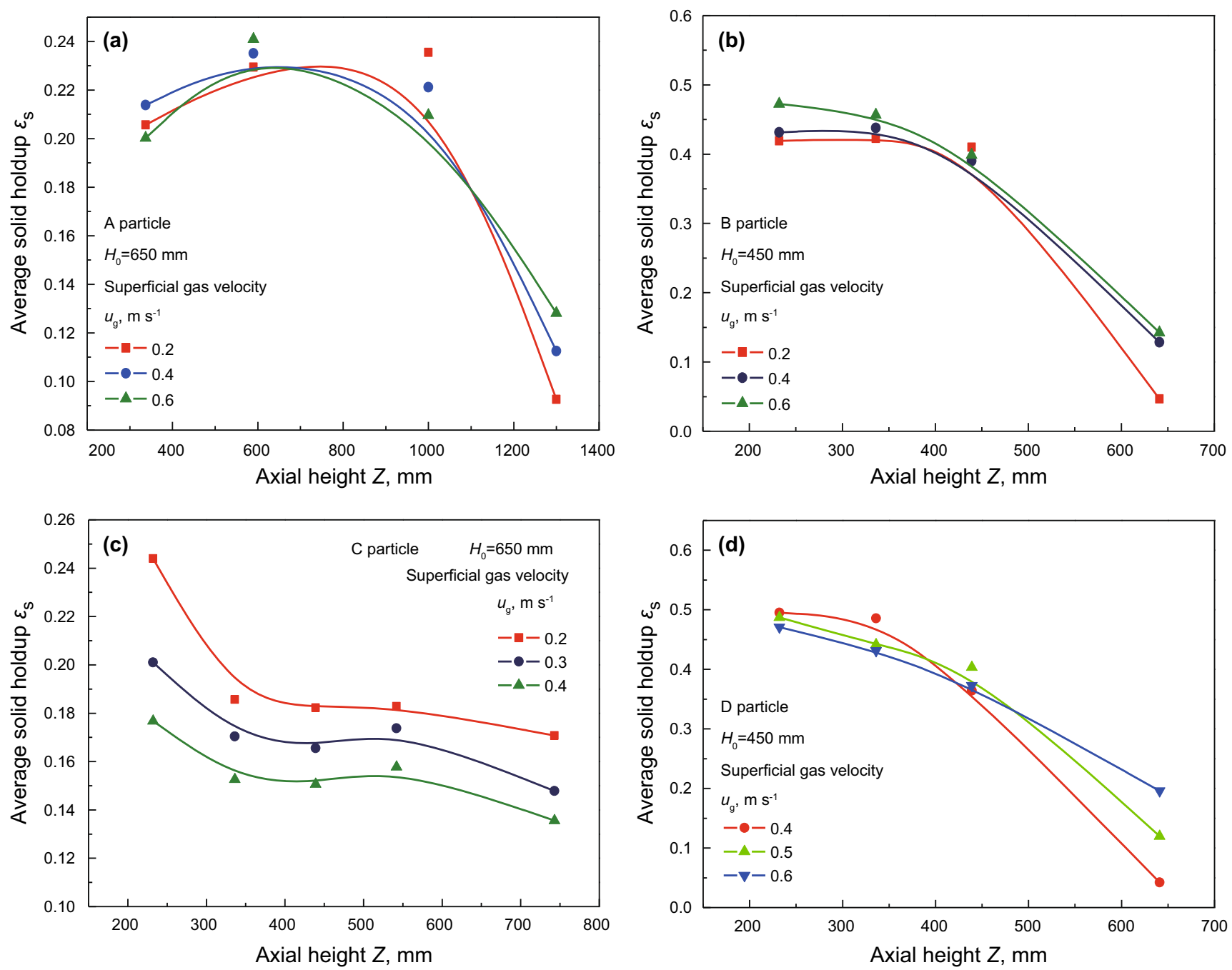

Fig. 8 Axial average solid holdup distribution in the dense phase

Figure 9 shows the effect of superficial gas velocity on the bed expansion coefficient based on $R_{\varepsilon}$. The bed expansion coefficient increased in proportion to the superficial gas velocity. That is why bed expansion coefficients of particles $\mathrm{A}$ and $\mathrm{C}$ were bigger than those of particles $\mathrm{B}$ and $\mathrm{D}$. This phenomenon can be explained by the following aspects. On the one hand, the diameter of particles was in direct proportion to the weight of the particles, which indicated that heavier particles were more difficult to be expanded than fine particles. On the other hand, the increase in particles diameter further gave rise to the increase in the bubble diameter in the dense bed. As a result, big bubbles had higher rising velocity which weakened the expansion of the dense bed. This conclusion is similar to the study based on bed height ratio $\left(R_{h}\right)$.

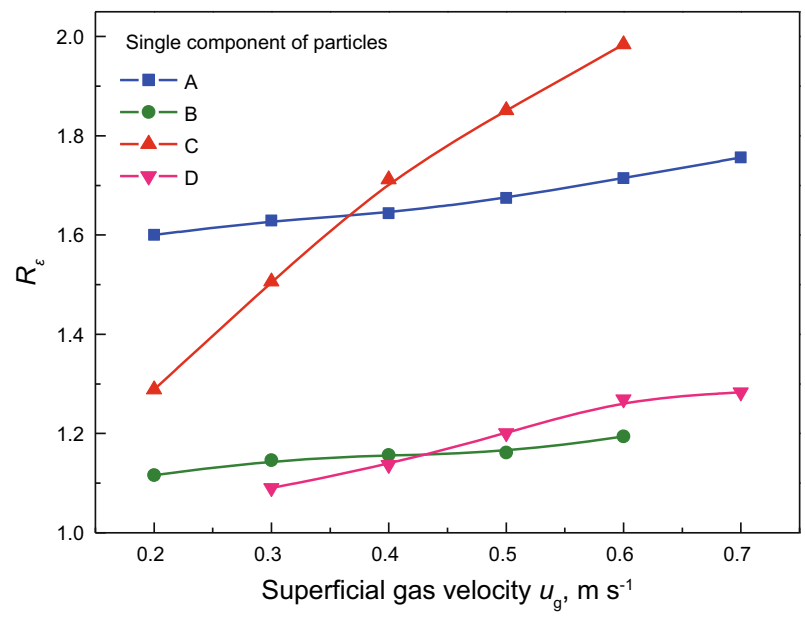

Fig. 9 Bed expansion coefficient based on solid content ratio 


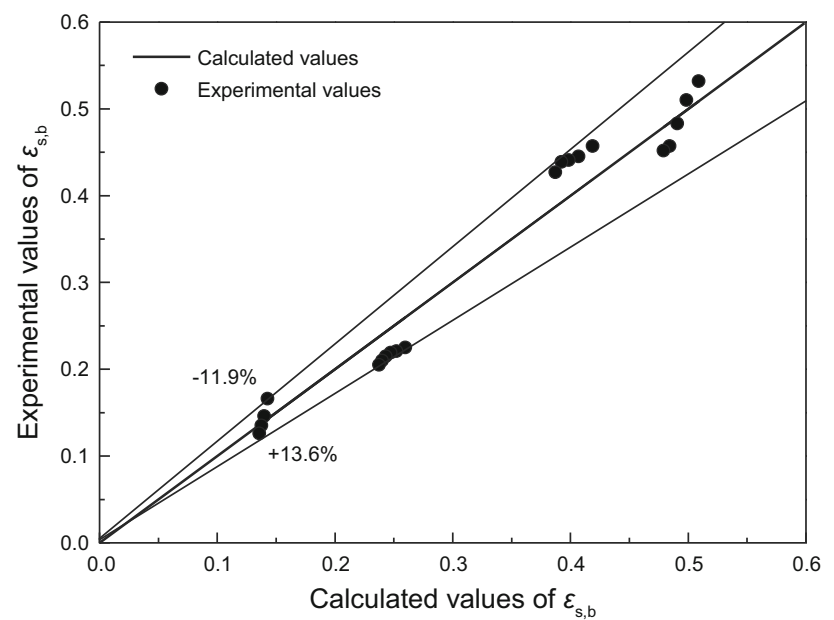

Fig. 10 Comparison between calculated and experimental values of average solid holdup in the dense phase

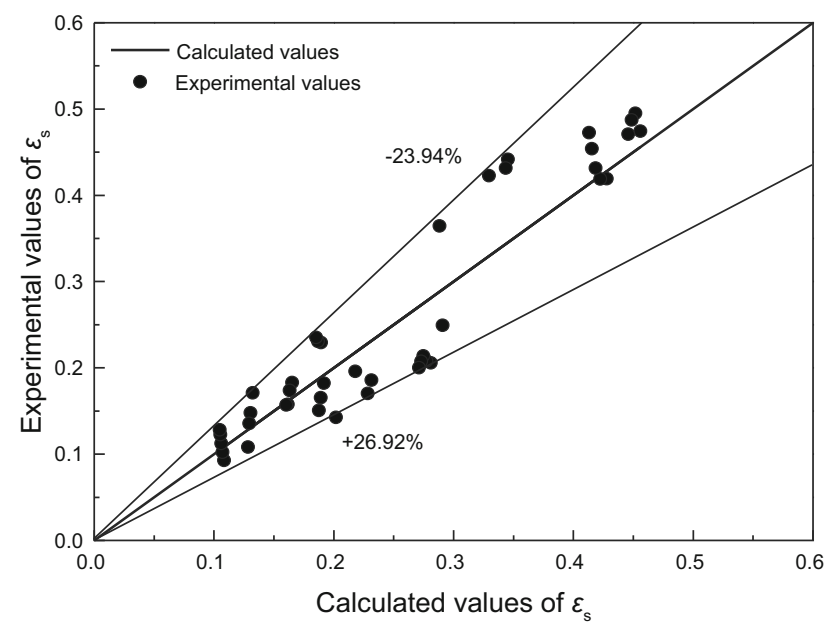

Fig. 11 Comparison between calculated and experimental values of axial average solid holdup distribution in the dense phase

\section{Correlation development}

Correlations of average solid holdup, axial average section solid holdup and bed expansion coefficient were proposed based on the analysis of experimental data and previous studies. Comparison between the calculated result and the experimental data was made to show the feasibility of the correlations.

\subsection{The correlation of average solid holdup}

Analysis of the experimental results clearly highlights the significant combined influence of superficial gas velocity, particle diameters and initial solid holdup on the average solid holdup of the particles. The Reynolds number $\left(R e=\left(d_{\mathrm{p}} u_{\mathrm{g}} \rho_{\mathrm{g}}\right) / \mu\right)$ was used to show the effect of operation conditions and properties. The correlation built by the least squares method is represented as follows:

$\varepsilon_{\mathrm{s}, \mathrm{b}}=1.7715 \operatorname{Re}^{-0.0714} \varepsilon_{\mathrm{s}, 0}^{1.8669}$

where $\varepsilon_{\mathrm{s}, \mathrm{b}}$ means the solid holdup of the fluidized bed. As shown in Eq. (5), the average solid holdup of particles increased with increasing diameter and initial solid holdup and decreased with the increase in superficial gas velocity. Figure 10 shows how this was in good agreement with the experimental result.

Figure 10 shows that the calculated values were in good agreement with the experimental data. The deviations were within $-11.9 \% \sim 13.6 \%$, demonstrating the reliable fitting of this correlation to predict the average solid holdup of the particles.

\subsection{The correlation of axial average section solid holdup}

As shown above, superficial gas velocity $\left(u_{\mathrm{g}}\right)$, axial height of the dense phase $(h)$, initial solid holdup $\left(\varepsilon_{\mathrm{s}, 0}\right)$ and the properties of particles together affected the distribution of the axial average solid holdup of different size particles. The Reynolds number was used to illustrate the effect of superficial gas velocity and particle properties. The ratio of the height to the diameter of fluidized bed was used to show the effect of the axial height of the dense phase. The correlation is shown as follows:

$\varepsilon_{\mathrm{s}, \mathrm{b}}=0.6310 R e^{-0.0319} \varepsilon_{\mathrm{s}, 0}^{0.6732}\left(\frac{h}{D}\right)^{-0.7047}$

where $h$ means the height of the fluidized bed, m, and $D$ means the diameter of the fluidized bed, $\mathrm{m}$. As shown in Eq. (6), the average solid holdup of different component particles increased with increasing initial solid holdup and decreased with increasing superficial gas velocity. Meanwhile, the average solid holdup decreased along the axial height.

Figure 11 shows the comparison between the calculated average solid holdup and the experimental data. The average relative error was $15.4 \%$, according to which the correlation of the axial average solid holdup was feasible.

\subsection{The correlation of bed expansion coefficient}

The solid content ratio $\left(R_{\varepsilon}\right)$ is used to calculate the bed expansion coefficient in the situation of high superficial gas velocity. The correlation is shown as follows:

$R_{\varepsilon}=0.1067 R e^{0.1861}\left(\frac{d_{\mathrm{p}}}{D}\right)^{-0.2793}$ 


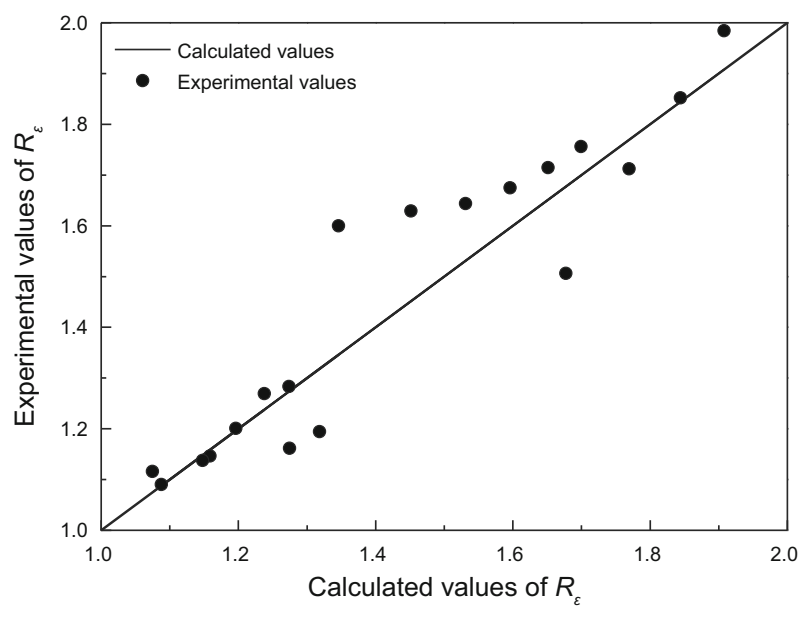

Fig. 12 Comparison between calculated and experimental values of $R_{\varepsilon}$

where $D$ means the diameter of the fluidized bed, $\mathrm{m}$, and $d_{\mathrm{p}}$ is the diameter of particles, $\mathrm{m}$. The correlation shown in Eq. (7) indicated that the solid content ratio increased with increasing superficial gas velocity and decreased with the increase in particle diameter. This showed that Eq. (7) is in good agreement with the analysis above. Figure 12 shows the comparison between the calculated bed expansion efficient and the experimental data. The average relative error was only $4.35 \%$, which means that the bed expansion efficient correlation based on $R_{\varepsilon}$ was reliable.

\section{Conclusions}

In this work, the fluidization characteristics of different sized particles were investigated at various superficial gas velocities in the dense phase. Predictive correlations between average solid holdup in the dense phase, axial average solid holdup and bed expansion coefficient were also established and discussed. The following conclusions are obtained:

(1) The average solid holdup in the dense zone decreases with increasing superficial gas velocity and decreases with a decrease in initial solid holdup.

(2) The axial average section solid holdup decreases with increasing bed height and increasing superficial gas velocity.

(3) The bed expansion coefficient increases with the increase in superficial gas velocity and increases with a decrease in initial solid holdup.

Open Access This article is distributed under the terms of the Creative Commons Attribution 4.0 International License (http://crea tivecommons.org/licenses/by/4.0/), which permits unrestricted use, distribution, and reproduction in any medium, provided you give appropriate credit to the original author(s) and the source, provide a link to the Creative Commons license, and indicate if changes were made.

\section{References}

Ahuja GN, Patwardhan AW. CFD and experimental studies of solids hold-up distribution and circulation patterns in gas-solid fluidized beds. Chem Eng J. 2008;143(1-3):147-60.

Avidan AA, Yerushalmi J. Bed expansion in high velocity fluidization. Powder Technol. 1982;32(2):223-32.

Cai J, Li T, Sun QW, et al. Solid concentration distribution in a gassolid fluidized bed. Process Eng. 2008;8(5):839-44.

Cui G, Liu MX, Lu CX. Axial distribution and development of solids hold-up in a fluidized bed-riser coupled reactor. Chin J Process Eng. 2014;14(4):556-61 (in Chinese).

Fan Q, Bai G. The evaluation of oil sand bitumen produced from inner Mongolia. Pet Sci Technol. 2015;33(4):437-42.

Gao JS, Xu T, Wang G, et al. Reaction behavior of oil sand in fluidized-bed pyrolysis. Pet Sci. 2013;10:562-70.

Geldart D. Types of gas fluidization. Powder Technol. 1973;7(5):285-92.

Lu CX, Xu CM, Li SY, et al. A process and apparatus of direct fluid coking for oil sands. China Patent CN 101358134A; 2008 (in Chinese).

Lu CX, Xu YF, Shi MX, et al. Bed expansion in the dense region of FCC turbulent fluidized bed. $J$ Chem Ind Eng. 1996a;47(1):110-3 (in Chinese).

Lu CX, Xu YF, Shi MX, et al. Study of the radial distribution of voidage in gas-solid turbulent fluidized beds. J Chem Ind Eng. 1996b;47(1):110-3 (in Chinese).

Meng M, Hu HQ, Zhang QM, et al. Pyrolysis behaviors of Tumuji oil sand by thermogravimetry (TG) and in a fixed bed reactor. Energy Fuels. 2007;21(4):2245-9.

Painter P, Williams P, Lupinsky A. Recovery of bitumen from Utah tar sands using ionic liquids. Energy Fuels. 2010;24(9): 5081-8.

Ren SL. Research progress in water-based bitumen extraction from oil sands. Chin J Chem Eng. 2011;9(62):2406-12 (in Chinese).

Sun D, Wang SY, Lu HL, et al. A second-order moment method of dense gas-solid flow for bubbling fluidization. Chem Eng Sci. 2009;64(23):5013-27.

Tang J, Chen XN, Zhang YM, et al. Bed expansion in the dense region of a FCC turbulent fluidized bed. J Chem Ind Eng. 2012;47(1):110-3 (in Chinese).

Wang ZC. Structure changes of asphaltene oil sands during pyrolysis. Doctoral dissertation. Northeast Dianli University; 2015.

Xu XQ, Wang HY, Zeng DW, et al. Research progress in application of the oil sands. Liaoning Chem Ind. 2008;37(4):268-71 (in Chinese).

Zhang C, Wang DM, Zhang BB, et al. Catalytic pyrolysis behaviors of Xinjiang Tuoli oil sand. Chin J Process Eng. 2014;14(3):456-61 (in Chinese).

Zhang YL, Ye M, Zhao YF, et al. Emulsion phase expansion of Geldart A particles in bubbling fluidized bed methanation reactors: a CFD-DEM study. Powder Technol. 2015;275(8):199-210.

Zhao RY, Wang T, Zhang C, et al. Research progress of oil sands wettability. Oilfield Chem. 2014;31(4):620-5 (in Chinese).

Zhu LY, Fan YP, Lu CX. Flow characteristics of catalytic particles in the pre-lifting structure with two strands of catalyst inlets. Chin J Process Eng. 2014;14(1):9-15 (in Chinese). 